\title{
Faktor-Faktor yang Berhubungan dengan Pernikahan Usia Dini di Desa Lamtamot Kecamatan Lembah Seulawah Aceh Besar Tahun 2017
}

\author{
Factors Relating to Early Marriage in Lamtamot Village, Lembah Seulawah \\ District Aceh Besar 2017
}

Asmaul Husna $^{* 1}$, Faradilla Safitri ${ }^{2}$, Nuzulul Rahmi ${ }^{3}$

${ }^{1,2}$ Program Studi D-IV Kebidanan, Fakultas Ilmu Kesehatan, Universitas Ubudiyah Indonesia, Banda Aceh, Indonesia

*Korespondensi Penulis: asmaulhusna@uui.ac.id

\begin{abstract}
Abstrak
Menurut United Nations Development Economic and Social Affairs (UNDESA, 2010), Indonesia merupakan negara ke-37 dengan jumlah pernikahan dini terbanyak di dunia di tahun 2007. Untuk level ASEAN, tingkat pernikahan dini di Indonesia berada di urutan kedua terbanyak setelah Kamboja. Menurut Riskesdes (2011), perempuan muda di Indonesia dengan usia 10-14 tahun menikah sebanyak $0,2 \%$ atau lebih dari 22.000 wanita muda berusia 10-14 tahun di Indonesia sudah menikah. Jumlah dari perempuan muda berusia 15-19 tahun yang menikah lebih besar jika dibandingkan dengan laki-laki muda berusia 15-19 tahun (11,7\% perempuan dan 1,6\% laki-laki usia 15-19 tahun). Selain itu jumlah aborsi di Indonesia diperkirakan mencapai 2,3 juta pertahun. Sekitar 750.000 diantaranya dilakukan oleh remaja (BKKBN, 2013). Populasi dalam penelitian ini adalah seluruh remaja putri yang aada di Desa Lamtamot Kecamatan Lembah Seulawah Kabupaten Aceh Besar sebanyak 120 remaja putri. Penelitian ini telah dilakukan di Desa Lamtamot Kecamatan Lembah Seulawah Kabupaten Aceh Besar Tahun 2017 pada tanggal 22 s/d 30 Mei 2017. Sampel adalah sebagian atau wakil dari polulasi yang diteliti. Sampel dalam penelitian ini adalah sampel total (total sampling) yaitu seluruh remaja putri di Desa Lamtamot Kecamatan Lembah Seulawah Kabupaten Aceh Besar sebanyak 120 remaja putri. Hasil analisis bivariat terdapat hubungan antara pengetahuan dan sikap remaja putri dengan pernikahan di usia dini di desa lamtamot kecamatan lembah seulawah kabupaten aceh besar tahun 2017. Diharpakan penelitian ini dapat memotivasi masyarakat khususnya remaja untuk menambah pengetahuan tentang pernikahan usia dini dan dampaknya, serta mengerti bagaimana sikap yang tepat untuk mencegah terjadinya pernikahan usia dini.
\end{abstract}

Kata kunci : pengetahuan, sikap, pernikahan Usia Dini

\begin{abstract}
According to the United Nations Development Economic and Social Affairs (UNDESA, 2010), Indonesia is the 37th country with the highest number of early marriages in the world in 2007. For the ASEAN level, the rate of early marriage in Indonesia is second most after Cambodia. According to the Riskesdes (2011), young women in Indonesia aged 10-14 are married as much as $0.2 \%$ or more than 22,000 young women aged 10-14 years in Indonesia are married. The number of young women aged 15-19 years who are married is greater when
\end{abstract}


compared to young men aged 15-19 years (11.7\% women and $1.6 \%$ men aged $15-19$ years). In addition, the number of abortions in Indonesia is estimated to reach 2.3 million per year. Around 750,000 of them are carried out by teenagers (BKKBN, 2013). The population in this study were all young women who were in Lamtamot Village, Seulawah Valley District, Aceh Besar Regency as many as 120 young women. This research has been carried out in Lamtamot Village, Lembah Seulawah Subdistrict, Aceh Besar Regency, 2017 on 22 to 30 May 2017. Samples are in part or representative of the surveyed pollulations. The sample in this study was a total sample, namely all young women in Lamtamot Village, Seulawah Valley District, Aceh Besar District, as many as 120 young women. The results of bivariate analysis have a relationship between the knowledge and attitudes of young women with marriage at an early age in the village of Lamtamot in the valley district of Seulawah Besar Aceh Regency in 2017. The conclusions obtained from the research are as follows: early and the impact, and understand how the right attitude to prevent the occurrence of early marriage.

Keywords: knowledge, attitude, early marriage

\section{PENDAHULUAN}

Komplikasi dari kehamilan dan persalinan merupakan penyebab utama kematian anak perempuan berusia 15 sampai 19 tahun di negara-negara berkembang. Dari 16 juta remaja perempuan yang melahirkan setiap tahun diperkirakan $90 \%$ sudah menikah dan 50 ribu diantaranya telah meninggal. Selain itu resiko terjadinya kematian ibu dan kematian bayi yang baru lahir 50\% lebih tinggi dilahirkan oleh ibu di bawah usia 20 tahun antara ibu dibandingkan pada ibu wanita yang hamil di usia 20 tahun ke atas (Koliman, 2009).

Menurut United Nations Development Economic and Social Affairs (UNDESA, 2010), Indonesia merupakan negara ke-37 dengan jumlah pernikahan dini terbanyak di dunia di tahun 2007. Untuk level ASEAN, tingkat pernikahan dini di Indonesia berada di urutan kedua terbanyak setelah Kamboja. Menurut Riskesdes (2011), perempuan muda di Indonesia dengan usia 10-14 tahun menikah sebanyak $0,2 \%$ atau lebih dari 22.000 wanita muda berusia 10-14 tahun di Indonesia sudah menikah. Jumlah dari perempuan muda berusia 15-19 tahun yang menikah lebih besar jika dibandingkan dengan laki-laki muda berusia 15-19 tahun (11,7\% perempuan dan 1,6\% laki-laki usia 15-19 tahun). Selain itu jumlah aborsi di Indonesia diperkirakan mencapai 2,3 juta pertahun. Sekitar 750.000 diantaranya dilakukan oleh remaja (BKKBN, 2013).

Departemen Kesehatan Republik Indonesia (2011), mengemukakan bahwa di Indonesia pernikahan dini 15-20\% dilakukan oleh pasangan baru. Secara Nasional pernikahan dini usia pengantin di bawah 19 tahun sebanyak 26,9\%. Bahkan beberapa daerah melebihi angka 
tersebut, seperti di Jawa Timur (39,43\%), Kalimantan (35,48\%), Jambi (30,63\%), Jawa Barat (36\%), dan Jawa Tengah $(27,48 \%)$.

Menurut penelitian yang telah dilakukan oleh Desirianti, (2014) menujukkan dari Dan uji statistik chi-square di peroleh nilai p-value $0,025(\mathrm{P}<0,05)$ berarti adanya hubungan antara pegetahuan dengan usia pernikahan dini, sesui dengan kriteria, bahwa dari 15 orang responden yang memiliki sikap positif terdapat hanyak 2 orang atau $(13,3 \%)$ responden yang menikah di usia dini, sedang kandari 16 responden yang memiliki Sikap negative ditemukan juga hanya 12 orang saja $(75,0 \%)$ yang menikah di usiadini. Dan setelah dilakukan uji statistik chi-square di peroleh nilai p-value $0,002(\mathrm{P}<0,05)$ berarti adanya hubungan antara sikap dengan usia pernikahan dini.

\section{METODE PENELITIAN}

Penelitian ini menggunakan jenis penelitian yang bersifat survey analitikdengan desain cross-sectional. Populasi dalam penelitian ini adalah seluruh remaja putri yang aada di Desa Lamtamot Kecamatan Lembah Seulawah Kabupaten Aceh Besar sebanyak 120 remaja putri. Penelitian ini telah dilakukan di Desa Lamtamot Kecamatan Lembah Seulawah Kabupaten Aceh Besar Tahun 2017 pada tanggal 22 s/d 30 Mei 2017.Sampel adalah sebagian atau wakil dari polulasi yang diteliti. Sampel dalam penelitian ini adalah sampel total (total sampling) yaitu seluruh remaja putri di Desa Lamtamot Kecamatan Lembah Seulawah Kabupaten Aceh Besar sebanyak 120 remaja putri.

Analisis univariat bertujuan untuk menjelaskan atau mendeskripsikan karakteristik setiap variabel penelitian. Pada analisis univariat peneliti hanya melihat distribusi frekuensi dan persentase setiap variabel yang diteliti yaitu kejadian diare, pengetahuan dan sikap ibu. Analisis bivariat pada penelitian ini menggunakan uji statistik chi square, dengan batas kemaknaan $(\alpha=0,05)$ atau Confident Level $(\mathrm{CL})=95 \%$. Diolah dengan menggunakan komputerisasi. Untuk analisa bivariat pada penelitian ini adalah melihat hubungan antara pengetahuan,sikap terhadap pernikahan di usia dini. Nilai yang dilihat untuk mengetahui kedua variabel ada hubungan adalah dengan nilai $\mathrm{p}<0,05$. 


\section{HASIL DAN PEMBAHASAN}

Tabel 1. Hubungan Pengetahuan Remaja Putri dengan Pernikahan Usia Dini di Desa Lamtamot Kecamatan Lembah Seulawah Kabupaten Aceh Besar Tahun 2017

\begin{tabular}{|c|c|c|c|c|c|c|c|c|}
\hline \multirow{3}{*}{ No } & \multirow{3}{*}{ Pengetahuan } & \multicolumn{4}{|c|}{ Pernikahan Usia Dini } & \multirow{2}{*}{\multicolumn{2}{|c|}{ Total }} & \multirow{3}{*}{$\begin{array}{c}P \\
\text { Value }\end{array}$} \\
\hline & & \multicolumn{2}{|c|}{ Ya } & \multicolumn{2}{|c|}{ Tidak } & & & \\
\hline & & $\mathbf{f}$ & $\%$ & $\mathbf{f}$ & $\%$ & $\mathbf{n}$ & $\%$ & \\
\hline 1 & Baik & 32 & 46,4 & 37 & 53,6 & 69 & 100 & 0,004 \\
\hline 2 & Kurang baik & 38 & 74,5 & 13 & 25,5 & 51 & 100 & \\
\hline
\end{tabular}

Tabel 2. Hubungan Sikap Remaja Putri dengan Pernikahan Usia Dini di Desa Lamtamot Kecamatan Lembah Seulawah Kabupaten Aceh Besar Tahun 2017

\begin{tabular}{|c|c|c|c|c|c|c|c|c|}
\hline \multirow{3}{*}{ No } & \multirow{3}{*}{ Sikap } & \multicolumn{4}{|c|}{ Pernikahan Usia Dini } & \multirow{2}{*}{\multicolumn{2}{|c|}{ Total }} & \multirow{3}{*}{$\begin{array}{c}P \\
\text { Value }\end{array}$} \\
\hline & & \multicolumn{2}{|c|}{ Ya } & \multicolumn{2}{|c|}{ Tidak } & & & \\
\hline & & $\mathbf{f}$ & $\%$ & $\mathbf{f}$ & $\%$ & $\mathbf{n}$ & $\%$ & \\
\hline 1 & Positif & 40 & 70,2 & 17 & 29,8 & 57 & 100 & 0,020 \\
\hline 2 & Negatif & 30 & 47,6 & 33 & 52,4 & 63 & 100 & \\
\hline
\end{tabular}

\section{Pembahasan}

1. Hubungan Pengetahuan Remaja Putri dengan Pernikahan Usia Dini

Berdasarkan hasil penelitian yang telah dilakukan dapat diketahui bahwa dari 69 orang responden yang memiliki berpengetahuan baik diketahui hanya 32 orang atau $(46,4 \%)$ responden yang menikah di usia dini, sedangkan dari 51responden yang memiliki berpengetahuan kurang baik ditemukan ternyata 38 orang atau $(74,5 \%)$ yang menikah di usia dini.Selanjutnya dari analisa menggunakan chi square $\left(X^{2}\right)$ dengan tingkat kemaknaan $(\alpha)$ adalah $\leq 0,05$ didapatkan nilai Probabilitas $(p) 0,004$. Sehingga dapat disimpulkan bahwa ada hubungan yang singnifikan antara hubungan PengetahuanRemaja PutriDengan Pernikahan Usia Dini di Desa Lamtamot Kecamatan Lembah Seulawah Kabupaten Aceh Besar Tahun 2017.

Hasil penelitian ini sejalan dengan penelitian yang dilakukan oleh mira (2013) dengan judul faktor-faktor yang mempengaruhi terjadinya pernikahan dini pada remaja Di Keluruhan Rowosari Kecamatan Tembalan Kota Semarang "Hasil penelitian yang menunjukkan bahwa ada hubungan pernikahan dini dengan pengetahuan dan tingkat pendidikan didapatkan 0,015 yang artinya nilai $\mathrm{p}<0,05$ dan dapat disimpulkan adanya hubungan pengetahuan dengan terjainya pernikahan dini. 
Hasil penelitian oleh yang berjudul "hubungan pengetahuan dan sikap remaja putri dengan pernikahan usia dini di Desa Durian Kawan Kecamatan Kluet Timur Kabupaten Aceh Selatan Tahun 2015.responden yang memiliki tingkat pengetahuan baik diketahui hanyak 3 orang atau $(25,0 \%)$ responden yang menikah di usia dini, sedangkan dari 9 responden yang memiliki tingkat pengetahuan cukup di temukan juga hanya 3 orang saja $(33,3$. uji statistik chi-square di peroleh nilai p-value $0,025(\mathrm{P}<0,05)$ yang artinya bahwa nilai $p$-value tersebut lebih kecil dari pada nilai tetapan $\alpha(0,05)$ maka dapat di tarik kesimpulan bahwa terdapat hubungan yang signifikan antara pengetahuan hubungan dengan usia pernikahan dini.

Menurut Ariani (2014), pengetahuan (knowledge) merupakan hasil rasa keingintahuan manusia Dengan sesuatu dan hasrat untuk meningkatkan harkat sehingga kehidupan menjadi lebih baik dan nyaman yang berkembang sebagai upaya memenuhi kebutuhan manusia baik dimasa sekarang maupun dimasa depan. Pengetahuan hanya sekedar menjawab pertanyaan what, misalnya apa alam, apa manusia, apa air dan lainnya.

Pengetahuan itu sendiri dipengaruhi oleh faktor pendidikan formal. Pengetahuan sangat erat hubungannya dengan pendidikan, dimana diharapkan bahwa dengan pendidikan yang tinggi maka orang tersebut akan semakin luas pula pengetahuannya. Akan tetapi perlu ditekankan, bukan berarti seseorang yang berpendidikan rendah mutlak berpengetahuan rendah pula. Hal ini mengingat bahwa peningkatan pengetahuan tidak mutlak diperoleh dari pendidikan formal saja, akan tetapi dapat diperoleh melalui pendidikan non formal. Pengetahuan seseorang tentang suatu obyek mengandung dua aspek, yaitu aspek positif dan aspek negatif. Kedua aspek ini yang akan menentukan sikap seseorang. Semakin banyak aspek positif dan objek yang diketahui, maka akan menimbulkan sikap makin positif Dengan objek tertentu. Menurut WHO (World Health Organization), salah satu bentuk objek kesehatan dapat dijabarkan oleh pengetahuan yang diperoleh dari pengalaman sendiri (Wawan, A dan Dewi M, 2010).

Pengetahuan merupakan hasil tahu dan ini terjadi setelah orang melakukan penginderaan Dengan suatu objek tertentu. Jika seorang wanita mempunyai pengetahuan yang cukup tentang pernikahan dini, maka ia akan berusaha untuk menikah pada usia dewasa. Secara psikis wanita yang nikah pada usia muda belum siap untuk memikul tanggung jawab sebagai orang tua bagi anak-anaknya (Yuliza, 2013). 
Peneliti beramsumsi bahwa dalam penelitian ini terdapat hubungan antara pengetahuan dengan remaja putri dalam melakukan pernikahan dini,remaja menikah di usia dini, penyebabnya mereka melakukankannya macam-macam ada karena paksaan keluarga, keluarga kurang mampu dan bahkan ada karena keingginan sendiri, maka disini sangat di butuhkan turun tanggan dari tenaga kesehatan untuk memberi tawu apa efek dari pernikahan dini dan bisa menambah pengetahuan warga setempat,bahwa dengan kurangnya pengetahuan tentang pernikahan dini dengan demikian wanita kurang mengerti tentang resiko yang akan terjadi akibat dari pernikahan dini tersebut dan apabila berpengatahuan baik maka sedikit tidaknya wanita mengerti tentang resiko yang akan timbul nantinya setelah menikah. Oleh karena itu pengetahuan sangat berpengaruh Dengan pernikahan di usia dini.

2. Hubungan Sikap Remaja Putri dengan Pernikahan Usia Dini

Berdasarkan hasil penelitian yang telah dilakukan dapat diketahui bahwa dari 57 orang responden yang memiliki sikap positif diketahui hanya 40 orang atau $(70,2 \%)$ responden yang menikah di usia dini, sedangkan dari 63responden yang memiliki sikap negatif ditemukan ternyata 30 orang atau $(47,6 \%)$ yang menikah di usia dini.

Selanjutnya dari analisa menggunakan chi square $\left(X^{2}\right)$ dengan tingkat kemaknaan $(\alpha)$ adalah $\leq$ 0,05 didapatkan nilai Probabilitas ( $p$ )0,020. Sehingga dapat disimpulkan bahwa ada hubungan yang singnifikan antara hubungan SikapRemaja PutriDengan Pernikahan Usia Dini di Desa Lamtamot Kecamatan Lembah Seulawah Kabupaten Aceh Besar Tahun 2017.

Hasil penelitian oleh yang berjudul "hubungan pengetahuan dan sikap remaja putri dengan pernikahan usia dini di Desa Durian Kawan Kecamatan Kluet Timur Kabupaten Aceh Selatan Tahun 2015.dari 15 orang responden yang memiliki sikap positif di ketahui hanyak 2 orang atau $(13,3 \%)$ responden yang menikah di usia dini, sedangkan dari 16 responden yang memiliki Sikap negatif di temukan juga hanya 12 orang saja $(75,0 \%)$ yang menikah di usia dini. uji statistik chi-square di peroleh nilai $p$-value $0,002(\mathrm{P}<0,05)$ yang artinya bahwa nilai $p$-value tersebut lebih kecil dari pada nilai tetapan $\alpha(0,05)$ maka dapat di tarik kesimpulan bahwa terdapat hubungan yang signifikan antara sikap dengan usia pernikahan dini. 
Hasil penelitian ini sejalan dengan penelitian yang dilakukan oleh Harya (2008) dengan variabel independennya " hubungan sikap dengan terjadinya nikah dini Di Wilayah Kerja Puskesmas Lingkar Timur"Hasil penelitian menunjukkan bahwa ada hubungan Sikap terjadinya pernikahan dini di wilayah kerja Puskesmaas Lingkar Timur Bengkulu yang menunjukkan $p$-value sebesar $0,002<0,05$.

Sikap merupakan respons tertutup seseorang Dengan stimulus atau objek tertentu, yang sudah melibatkan faktor pendapat dan emosi yang bersangkutan (senang-tidak senang, setuju-tidak setuju, baik-tidak baik, dan sebagainya). Sikap didefenisikan sangat sederhana, yakni : "An individual's attitude is syndrome of response consistency with regard to object”. Jadi jelas di sini dikatakan bahwa sikap itu suatu sindrom atau kumpulan gejala dalam merespons stimulus atau objek. Sehingga sikap itu melibatkan pikiran, perasaan, perhatian dan gejala kejiwaan yang lain (Notoatmodjo, 2010).

Menurut Jahja (2011), sikap merupakan kesiapan atau keadaan siap untuk timbulnya suatu perbuatan atau tingkah laku. Sikap juga merupakan organisasi keyakinan-keyakinan seseorang mengenai objek atau situasi yang relatif ajek, yang memberi dasar kepada orang untuk membuat respons dalam cara tertentu. Sikap merupakan penentu dalam tingkah laku manusia, sebagai reaksi sikap selalu berhubungan dengan dua hal yaitu "like" atau "dislike" (senang atau tidak senang, suka atau tidak suka). Mengacu pada adanya faktor perbedaan individu (pengalaman, latar belakang, pendidikan dan kecerdasan), maka reaksi yang dimunculkan Dengan satu objek tertentu akan berbeda pada setiap orang.

Peneliti berasumsi bahwa dalam penelitian ini terdapat hubungan anatara sikap dengan remaja putri dalam melakukan pernikahan dini, terjadinya pernikahan dini diakibatkan karena sikap keluarga dan kepala keluarga dan sikap seorang remaja tersebut dan juga sikap lingkungan daerah tersebut, Seiring dengan membaiknya Sikap para remaja putri memiliki sikap positif dalam membuat keputusan mengenai perkawinan dan melahirkan, wanita yang sikap dasar positif kemungkinannya lebih kecil menikah pada masa remaja di bandingkan dengan Sikap mereka yang negatif, dan sikap lingkungannya sangat mempengaruhi Usia pernikahan dini Maka upaya yang harus dilakukankan adalah memberi penjelaan kepada masyarakat tersebut tentang apa dampak dari pernikahan dini itu bagai mana agar masyarakat lebih mengerti agar masyarakat tidak lagi melakukan pernikahan dini. 


\section{KESIMPULAN}

Berdasarkan hasil penelitian yang telah dilakukan maka peneliti dapat mengumpulkan hasil dari penenelitian sebagai berikut terdapat hubungan antara pengetahuan dan sikap remaja putri dengan pernikahan di usia dini di desa lamtamot kecamatan lembah seulawah kabupaten aceh besar tahun 2017.

\section{SARAN}

Diharpakan penelitian ini dapat memotivasi masyarakat khususnya remaja untuk menambah pengetahuan tentang pernikahan usia dini dan dampaknya, serta mengerti bagaimana sikap yang tepat untuk mencegah terjadinya pernikahan usia dini.

\section{DAFTAR PUSTAKA}

Ahmadi. 2009. Pengertian Pernikahan Dini. www.psychologymania.com. Diakses pada tanggal 6 maret 2016

Ariani, 2014. Aplikasi Metodologi Penelitian Kebidanana dan Kesehatan Reproduksi. Yogyakarta: Nuha Medika.

Arikunto, 2006. Prosedur Penelitian Suatu Pendekatan Praktek. Jakarta: Renika Cipta

Azwar, 2011. Sikap Manusia, Teori dana Pengukuran. Yogyakarta: Pustaka Pelaja

Desirianti, 2014 Hubungan Pengetahuan dan Sikap Remaja Putri Dengan Pernikahan Usia Dini Di Desa Durian Kawan Kecamatan Kluet Timur Kabupaten Aceh Selatan Tahun 2015.

Chandra, Budiman. 2008. Metodologi Penelitian Kesehatan. Jakarta : EGC

Darwinsyah, 2008. Psikologi Perkembangan Dewasa Muda. Jakarta: PT. GramediaWidiasarana Indonesia

Biro PusatStatitik 2009, Data ProvinsiSumatara Utara

Irene Astri 2011. Tingkat Pengetahuan Remaja Putri Tentang Pernikahan Dini pada Siswi di SMK Grafika Surakarta 